(rút ngắn thời gian tống máu). Rút ngắn thời gian tống máu phản ánh gián tiếp sự giảm co bóp cơ tim.

NC của chúng tôi đánh giá thay đổi hình thái giữa 2 nhóm xơ gan theo thang điểm Child Pugh thu được kết quả tăng LA, tăng Ds ở nhóm xơ gan Child - Pugh $C$ hơn so với nhóm xơ gan Child - Pugh $B, p<0.05$; EF giảm hơn ở nhóm xơ gan Child Pugh $C$, nhưng mức giảm nhẹ, không có ý nghĩa thống kê. Không có sự khác biệt vể Vd, CO giữa 2 nhóm. MCOT kéo dài, chỉ số Tei thất trái tăng hơn ở nhóm xơ gan Child - Pugh $\mathrm{C}$ so với nhóm xơ gan Child - Pugh $B, p<0.05$.

Nhiều NC cũng cho kết quả CNTTh thất trái ở $B N$ xơ gan luôn được bảo tồn khi nghỉ dù $B N$ ở giai đoạn xơ gan nhẹ hay nặng. Abd-El-Aziz và CS (2010) thấy tăng dần LA rõ theo mức độ xơ gan Child Pugh, $\mathrm{p}<0.05$, nhưng không thấy sự khác biệt về CO, EF\%, chỉ số Tei thất trái ${ }^{6}$. Yuan W và CS (2019) không thây sự khác biệt về Dd thất trái, độ dày thành thất, $\mathrm{EF}$ thất trái giữa các mức độ xơ gan?.

\section{KẾT LUÂN}

- Đường kính nhĩ trái, thất trái và khối lượng cơ thất trái ở bệnh nhân xơ gan do HBV lớn hơn so với người bình thường $(p<0.05)$. Đường kính nhĩ trái, đường kính thất trái tâm thu ở nhóm xơ gan Child - Pugh $C$ cũng lớn hơn nhóm xơ gan Child - Pugh B $(p<0,05)$.
- Phân suất tống máu giảm, thời gian tống máu thất trái rút ngắn, chỉ số Tei thất trái lớn hơn ở bệnh nhân xơ gan do HBV so với người bình thường $(p<0.05)$ và chỉ số Tei thất trái ở nhóm xơ gan Child - Pugh $C$ cũng lớn hơn nhóm $x \sigma$ gan Child - Pugh $B(p<0,05)$.

\section{TÀI LIẸU THAM KHẢO}

1. Nguyen VTT (2012). Hepatts B infecton in Vietnam: Current Issues and Future Challenges. AsiaPacifc Journal of Public Health; 24(2): 361-373.

2. Trân Văn Huy, Nguyến Thị Huyên Thương (2016). Nghiên cứu hiệu quả của tenofovir trên bệnh nhân xơ gan do virus viêm gan $B$. Tạp chí $Y$ Dước hoc - Trường Đai hoc Y Dước Huế; 32: 25-29.

3. Heintz K., Hollenberg S.M. (2018). Circulatory Physiology in Liver Disease. In: Nanchal R., Subramanian R. (eds). Hepatic Critical Care; Springer, Cham. https://doi.org/10.1007/978-3319-66432-3 2

4. World Health Organization (2015). Guidelines for the Prevention, Care and Treatment of Persons with Chronic Hepatitis B Infection. Pp. 1-166.

5. Sarin, S. K., Kumar, M., Lau, et al (2016). Asian-Pacific clinical practice guidelines on the management of hepatitis B: a 2015 update. Hepatology international, 10(1), 1-98. https://doi.org/10.1007/s12072-015-9675-4

6. Abd-El-Aziz T.A., Abdou M., Fathy A., et al. (2010). Evaluation of Cardiac Function in Patients with Liver Cirrhosis. Intern Med; (49), pp. 2547-2552.

7. Yuan W., Lu, H. Z., Mei, X., et al (2019). Cardiac health in patients with hepatitis B virusrelated cirrhosis. Medicine; 98(13), e14961. https://doi.org/10.1097/MD.0000000000014961

\title{
ĐÁNH GIÁ HIỆU QUẢ CỦA LACTULOSE ĐƯờNG THỤT TRONG ĐIỀU TRI BỆNH NÃO GAN Ở BỆNH NHÂN XƠ GAN
}

\section{TÓM TẮT}

Mục tiêu: Theo dõi đáp ứng lâm sàng và các biểu hiện cận lâm sàng của bệnh nhẩn xơ gan có hội chứng não gan với lactulose đường thụt. Đối tượng và phương pháp: Tổng số 32 bênh nhân chẩn đoản có biểu hiện tiền hôn mê gan được được đánh giá theo thang điểm West Haven, điểu trị bằng sử dung lactulose đường thụt hậu môn. Kết quả: Tỷ lệ bệnh nhân cải thiện nồng độ $\mathrm{NH} 3$ gặp ở 84,4\% bệnh nhân có cải thiện phân mức nồng độ NH3 máu, 15,6\% không cải thiện. Trạng thái tinh thần cải thiện ở

${ }^{1}$ Trung tâm tiêu hóa gan mật, Bệnh viện Bạch mai Bệnh viên $E$ trung ương

Chịu trách nhiệm chính: Nguyễn Công Long

Email: nguyenconglongbvbm@gmail.com

Ngày nhân bài: 2.7.2021

Ngày phản biên khoa hoc: 27.8.2021

Ngày duyệt bài: 3.9.2021

\section{Nguyễn Công Long1, Đào Văn Thành ${ }^{2}$}

$53,1 \%$ bệnh nhân. Theo mức độ nặng của hội chứng não gan theo phân loại West Haven $53,1 \%$ bệnh nhân có cải thiện. Kết luận: Lactulose đường thụt hậu môn có hiệu quả cải thiên nồng độ NH3 trong máu và triêu chứng lâm sàng đối với bệnh nhân có hội chứng nã̃o gan.

Tứ khoá: Lactulose; bệnh não gan; xơ gan

\section{SUMMARY}

\section{EVALUATION OF THERAPEUTIC OF EFFECTIVENESS OF LACTULOSE ENEMA IN HEPATIC ENCEPHALOPATHY}

Objective: We aimed to determine the effect of lactulose enema for treatment hepatic encephalopathy patients base on clinical and laboratory parameters. Subjects and methods: A total of 32 patients with hepatic encephalopathy treated with lactulose enema, West Haven Criteria was applied. Results: For overall response rate of the 32 patients who underwent 
lactulose enema, improvement in serum $\mathrm{NH} 3$ level was $84.4 \%$ and $15,6 \%$ not improvement. In term reversible neuropsychiatric was $53.1 \%$ patients. West Haven grade was improvement in $53.1 \%$. Conclusion: Administration of lactulose enematreatment was seen to improve serum NH3 level and provide better outcome in hepatic encephalopathy patients.

Key words: Lactulose; hepatic encephalopathy patients; cirrhosis

\section{I. ĐĂ̆T VẤN ĐỀ}

Bệnh não gan là những rối loạn chức năng của não thứ phát gây ra do tình trạng suy gan quá nặng ở bệnh nhân xơ gan, nó là một hội chứng gồm các rối loạn về thần kinh và tâm lý với các mức độ khác nhau. Các biểu hiện triệu chứng ở não của bệnh não gan không có sự khác biệt nhiều so với các nguyên nhân gây tổn thương não khác [1]. Nhiều công trình nghiên cứu đã chỉ ra rằng: tăng nồng độ ammonia chính là yếu tố chính trong sinh bệnh học của bệnh não gan[2,3]. Ở những bệnh nhân xơ gan, do các cấu trúc nhu mô gan lành dần bị thay thế bởi các tổ chức xơ làm tăng áp lực hệ tĩnh mạch cửa, dẫn đến các shunt cửa chủ do đó một lượng máu rất giàu ammonia có thể đi thẳng vào hệ tuần hoàn. Lactulose là một dissacharid không bị hấp thu ở ruột, nó chỉ bị phân giải bởi các vi khuẩn dissacharolic ở đại tràng thành acid organic, methane làm giảm $\mathrm{pH}$ của phân và ức chế hoạt động của các vi khuẩn lên men protein sinh $\mathrm{NH}_{3}$ nó cũng làm cho $\mathrm{NH}_{3}$ trong máu đào thải qua ruột dễ hơn. Đây là chất tốt nhất làm giảm nguồn $\mathrm{NH}_{3}$ ở đại tràng [4]. Ngoài ra, lactulose còn làm nhuận tràng, làm giảm thời gian vi khuẩn ở trong ruột giúp làm giảm sản xuất ammonia[5]. Nhưng ở Việt Nam chưa có nghiên cứu đánh giá cụ thể sự thay đổi của nồng độ NH3 trong quá trình điều trị Lactulose đường thụt ở bệnh nhân não gan do đó tôi thực hiện nghiên cứu này.

\section{II. ĐỐI TƯỢNG VÀ PHƯƠNG PHÁP NGHIÊN CỨU}

Đối tượng: Đối tượng nghiên cứu của chúng tôi gồm các bệnh nhân được chẩn đoán xơ gan có hội chứng não gan nằm điều trị tại khoa Tiêu hóa bệnh viện Bạch Mai. Thời gian từ 01/01/2014 đến 30/08/2014.

Đánh giá mức độ nặng bệnh não gan theo phân loại West Haven.

Giai đoạn 0: Không có thay đổi bất thường

Giai đoạn I: Khả năng tập trung giảm

Khả năng tính toán bị ảnh hưởng

Rối loạn giấc ngủ

Trạng thái kích thích nhẹ hoặc trầm cảm
Giai đoạn II: Thờ ơ

Giảm định hướng

Thay đổi về hành vi

Nói lắp, tư thế bất thường

Giai đoạn III: Mất định hướng

Mất hành vi

Lú lẫn

Giai đoan IV: Hôn mê.

Phương pháp: Điều trị hội chứng não gan ở bệnh nhân xơ gan theo phác đồ.

- Phác đồ điều trị bệnh nhân não gan.

- Trong đó: sử dung liều lactulose nghiên cứu là $600 \mathrm{ml} / \mathrm{ngày} \times 3$ ngày bằng đường thụt hậu môn. Thời gian điều trị 03 ngày.

Đánh giá bệnh nhân sau điều trị.

- Các yếu tố bênh não gan: trang thái tinh thần, test nối số $\dot{A}$, Flapping Tremor, nồng độ NH3 máu. Phân loại West Haven.

Xử lý số liệu :Sau khi thu thập đầy đủ các số liệu, quá trình xử lý được làm trên máy tính với phần mềm xử lý số liẹu SPSS 11.5 version, giá trị $\mathrm{P}<0,05$ được xác định là mức khác biệt có ý nghĩa thống kê.

\section{KẾT QUẢ NGHIÊN CỨU}

Bảng 1. Đặc điêm lâm sàng nhóm bệnh nhân nghiên cứu

\begin{tabular}{|c|c|c|c|}
\hline \multicolumn{2}{|c|}{$\begin{array}{c}\text { Triệu chứng lâm } \\
\text { sàng }\end{array}$} & $n=32$ & Tỷ lệ \% \\
\hline \multicolumn{2}{|c|}{ Mệt mỏi, kém ăn } & 32 & $100 \%$ \\
\hline \multicolumn{2}{|c|}{ Vàng da, vàng mắt } & 29 & $90,6 \%$ \\
\hline \multicolumn{2}{|c|}{ Phù } & 19 & $59,4 \%$ \\
\hline \multicolumn{2}{|c|}{ Cố trướng } & 27 & $84,4 \%$ \\
\hline \multicolumn{2}{|r|}{ Lách to } & 25 & $78,1 \%$ \\
\hline \multirow{3}{*}{ Gan } & Bình thường & 10 & $31,2 \%$ \\
\hline & To & 8 & $25 \%$ \\
\hline & Teo & 14 & $43,8 \%$ \\
\hline
\end{tabular}

- 100\% bệnh nhân có mệt, kém ăn.

- 29 bệnh nhân (chiếm 90,6\%) có vàng da, vàng mắt.

- 19 bệnh nhân (chiếm 59,4\%) có phù, 27 bệnh nhân (chiếm $84,4 \%$ ) có cố trướng.

Bảng 2. Đặc điểm cận lâm sàng nhóm bênh nhân nghiên cứu

\begin{tabular}{|c|c|c|c|c|}
\hline $\begin{array}{c}\text { Xét } \\
\text { nghiệm }\end{array}$ & $\begin{array}{c}\text { Trung bình } \\
\mathbf{N}=\mathbf{3 2}\end{array}$ & $\begin{array}{c}\text { Giá } \\
\text { trị }\end{array}$ & $\mathbf{n}$ & $\begin{array}{c}\text { Tỷ lệ } \\
\mathbf{\%}\end{array}$ \\
\hline $\begin{array}{c}\text { AST } \\
(\mathrm{UI} / \mathrm{L})\end{array}$ & $216,2 \pm 233,1$ & $\leq 37$ & 4 & 12,5 \\
\cline { 3 - 5 } & & $>37$ & 28 & 87,5 \\
\hline $\begin{array}{c}\mathrm{ALT} \\
(\mathrm{UI} / \mathrm{L})\end{array}$ & \multirow{2}{*}{$165,8 \pm 301,7$} & $\leq 40$ & 6 & 18,6 \\
\cline { 3 - 5 } & & $>40$ & 26 & 81,4 \\
\hline $\begin{array}{c}\mathrm{GGT} \\
(\mathrm{UI} / \mathrm{L})\end{array}$ & \multirow{2}{*}{$162,4 \pm 187,9$} & $\leq 40$ & 4 & 12,5 \\
\cline { 3 - 5 } & & $>40$ & 28 & 87,5 \\
\hline $\begin{array}{c}\text { Albumin } \\
\text { (g/l) }\end{array}$ & \multirow{2}{*}{$23,6 \pm 4,1$} & $\leq 35$ & 32 & 100 \\
\cline { 3 - 5 } & & $>35$ & 0 & 0 \\
\hline
\end{tabular}




\begin{tabular}{|c|c|c|c|c|}
\hline $\begin{array}{c}\text { Bilirubin } \\
(\mu \mathrm{mol} / \mathrm{l})\end{array}$ & $220 \pm 199,4$ & $\leq 35$ & 3 & 9,4 \\
\cline { 3 - 5 } & & $>35$ & 29 & 90,6 \\
\hline \multirow{2}{*}{$\mathrm{PT}(\%)$} & $45,8 \pm 12,5$ & $\leq 50$ & 28 & 87,5 \\
\cline { 3 - 5 } & & $>50$ & 4 & 12,5 \\
\hline $\begin{array}{c}\mathrm{NH}_{3} \\
(\mu \mathrm{mol} / \mathrm{l})\end{array}$ & \multirow{2}{*}{$158,2 \pm 44,4$} & $>60$ & 32 & 100 \\
\cline { 3 - 5 } & & $<60$ & 0 & 0 \\
\hline
\end{tabular}

$100 \%$ bệnh nhân có nồng độ $\mathrm{NH3}$ tăng trên $60 \mu \mathrm{mol} / \mathrm{l}$, giá trị trung bình của nhóm bênh nhân nghiên cứu là $158,2 \pm 44,4 \mu \mathrm{mol} / \mathrm{l}$, giá trị cao nhất là 239 umol/l.

Bảng 3: Tỉ lệ cải thiện các yêu tố bệnh não gan sau 3 ngày điều trị.

\begin{tabular}{|c|c|c|c|c|}
\hline \multirow{2}{*}{ Yêuu tố } & \multicolumn{2}{|c|}{ Cải thiện } & \multicolumn{2}{c|}{$\begin{array}{c}\text { Không cải } \\
\text { thiện }\end{array}$} \\
\cline { 2 - 5 } & $\mathbf{N}$ & Tỉ lệ \% & $\mathbf{N}$ & Tỉ lệ \% \\
\hline Tinh thân & 17 & 53,1 & 15 & 46,9 \\
\hline $\begin{array}{c}\text { Flapping } \\
\text { Tremor }\end{array}$ & 21 & 65,6 & 11 & 34,4 \\
\hline Test nối số A & 21 & 65,6 & 11 & 34,4 \\
\hline NH3 & 27 & 84,4 & 5 & 15,6 \\
\hline Chỉ số HE & 28 & 87,5 & 4 & 12,5 \\
\hline Phân loại & 22 & 68,8 & 10 & 31,2 \\
\hline
\end{tabular}

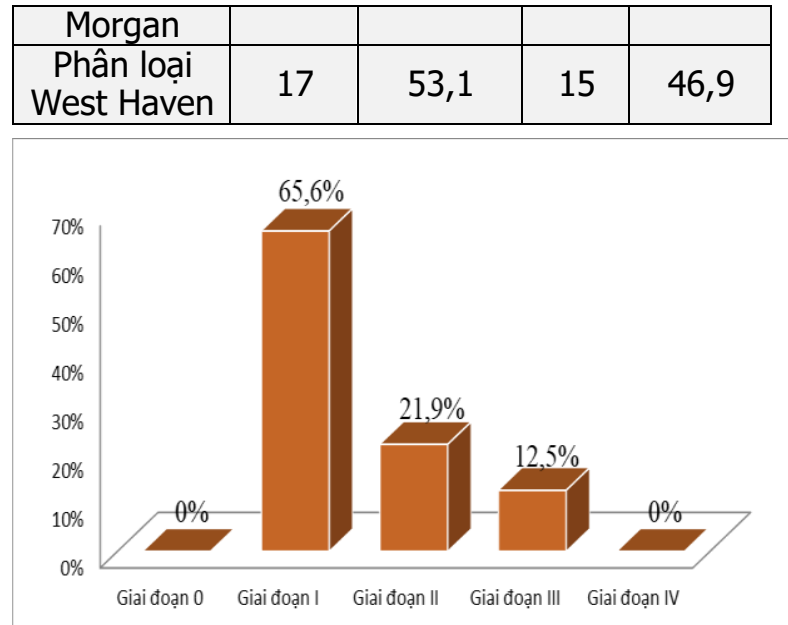

Biểu đổ 1: Đặc điểm phân bố bệnh não gan theo phân loại West Haven

Nhóm bệnh nhân nghiên cứu chủ yếu thuộc giai đoạn I theo phân loại mức độ nặng bệnh não gan của West Haven có 21 bệnh nhân (chiếm 65,6\%)

Bảng 4: Thay đổi giá trị các chỉ số bệnh não gan trước và sau 3 ngày điều trị.

\begin{tabular}{|c|c|c|c|}
\hline Chỉ số & Trước điều trị $(\mathbf{n}=\mathbf{3 2})$ & Sau 3 ngày điều trị(n = 32) & p \\
\hline TB nông độ $\mathrm{NH}_{3}(\mu \mathrm{mol} / \mathrm{l})$ & $158,2 \pm 44,4$ & $92,4 \pm 47,9$ & $<0,001$ \\
\hline TB phân mức NH3 & $2,66 \pm 0,97$ & $1,09 \pm 1,06$ & $<0,001$ \\
\hline TB test nối số A(giây) & $120,6 \pm 28,3$ & $86,4 \pm 20,9$ & $<0,001$ \\
\hline TB phân mức test A & $3,34 \pm 0,65$ & $2,63 \pm 0,66$ & $<0,001$ \\
\hline TB phân mức Flapping Tremor & $1,72 \pm 0,58$ & $1 \pm 0,71$ & $<0,001$ \\
\hline TB phân mức tinh thần & $1,47 \pm 0,72$ & $0,94 \pm 1,01$ & $<0,001$ \\
\hline TB phân độ Morgan & $3,28 \pm 0,58$ & $2,62 \pm 0,71$ & $<0,001$ \\
\hline TB chî số HE & $13,72 \pm 2,43$ & $8,94 \pm 4,69$ & $<0,001$ \\
\hline
\end{tabular}

\section{BÀN LUẬN}

Trong 32 bệnh nhân của nhóm nghiên cứu có 29 nam chiếm $90,6 \%$ và 3 nữ chiếm 9,4\%. Tỷ lệ nam/nữ $=9,7 / 1$. Có 2 nguyên nhân chính gây xớ gan được thấy là do nghiện rượu (chiếm 59,4\%) và do nhiếm virus viêm gan $B$ (chiếm 28,1\%). Trong nghiên cứu của chúng tôi, $100 \%$ bệnh nhân có nồng độ $\mathrm{NH3}$ máu tăng trên 60 ( $\mu \mathrm{mol} / \mathrm{l})$, giá trị trung bình của nhóm nghiên cứu là $158,2 \pm 44,4(\mu \mathrm{mol} / \mathrm{l})$, giá trị cao nhất lên tới $239(\mu \mathrm{mol} / \mathrm{l})$. Kết quả của chúng tôi cao hơn so với nghiên cứu của tác giả Barjesh Chander

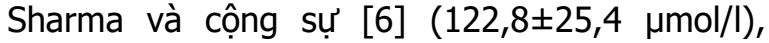
thấp hơn so với nghiên cứu của tác giả Yong-

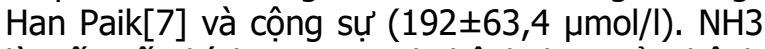
là yếu tố chính trong sinh bệnh học của bệnh não gan. Khi NH3 máu tăng, cùng với sự tích tụ của glutamine là nguyên nhân chính làm cho các tế bào hình sao phông lên dẫn đến rối loạn chức năng của tế bào hình sao. Các tế bào hình sao là thành phân quan trọng của hàng rào máu não, nó hấp thu các chất từ máu vào não, nó như cổng tiếp xúc với các neuron, liên quan đến việc truyền tín hiệu và điều chỉnh nồng độ ion trong não. Khi các tế bào hình sao phồng lển dẫn đến phù não, tăng áp lực nội sọ, thay đổi tính thấm của hàng rào máu não, rối loạn dẫn truyền thân kinh, liên quan đến việc kiểm soát nhận thức, làm phá hủy glutamate cân thiết để làm giảm nồng độ ammonia. Hậu quả là dẫn đến các rối loạn về thần kinh và nhận thức. Trong nghiên cứu của chúng tôi có 32 bệnh nhân bệnh não gan do xơ gan được điều trị bằng lactulose đường thụt hậu môn cùng với các biện pháp kết hợp khác và đánh giá kết quả sau 03 ngày điều trị. Tỉ lệ cải thiện: trong 32 bệnh nhân có 27 bệnh nhân (chiếm 84,4\%) cải thiện phân mức nồng độ NH3 máu với các mức độ khác nhau, có 5 bệnh nhân (chiếm 15,6\%) không cải thiện. Trước điều trị trung bình nông độ NH3 máu của nhóm nghiên cứu là 158,2 444,4 ( $\mu \mathrm{mol} / \mathrm{l})$, sau điều trị 01 ngày là $114,1 \pm 42,3(\mu \mathrm{mol} / \mathrm{l})$ với 
$\mathrm{p}<0,001$, sau điều trị 03 ngày là $92,4 \pm 47,9$ $(\mu \mathrm{mol} / \mathrm{l})$ với $\mathrm{p}<0,001$. Trước điều trị trung bình phân mức NH3 máu là 2,66 0,97 , sau điêu trị 01 ngày là $1,81 \pm 1,06$, sau điều trị 03 ngày là $1,09 \pm 1,06$ với với $p<0,001$. Kết quả của chúng tôi cũng tương tự nghiên cứu của tác giả YongHan Paik [7].

\section{KẾT LUÂN}

Qua nghiên cứu điều trị 32 bệnh nhân hội chứng não gan do xơ gan. Lactulose đường thụt hậu môn có hiệu quả cải thiện nồng độ $\mathrm{NH} 3$ trong máu và triệu chứng lâm sàng đối với bệnh nhân có hội chứng não gan.

\section{TÀl LIỆ THAM KHẢO}

1. Häussinger D, Kircheis G, Fischer R, Schliess F, vom Dahl S: Hepatic encephalopathy in chronic liver disease: a clinical manifestation of astrocyte swelling and low-grade cerebral edema? Journal of hepatology 2000, 32(6): 1035-1038.

2. Bhatia V, Singh R, Acharya SK: Predictive value of arterial ammonia for complications and outcome in acute liver failure. Gut 2006, 55(1):98-104.

3. Bohra A, Worland $T$, Hui $S$, Terbah $R$, Farrell A, Robertson $\mathbf{M}$ : Prognostic significance of hepatic encephalopathy in patients with cirrhosis treated with current standards of care. World journal of gastroenterology 2020, 26(18):2221-2231.

4. Said VJ, Garcia-Trujillo E: Beyond Lactulose: Treatment Options for Hepatic Encephalopathy. Gastroenterology nursing : the official journal of the Society of Gastroenterology Nurses and Associates 2019, 42(3):277-285.

5. Hadjihambi A, Arias $\mathbf{N}$, Sheikh $\mathbf{M}$, Jalan R: Hepatic encephalopathy: a critical current review. Hepatology international 2018, 12(Suppl 1):135-147.

6. Sharma BC, Sharma $P$, Lunia MK, Srivastava S, Goyal R, Sarin SK: A randomized, doubleblind, controlled trial comparing rifaximin plus lactulose with lactulose alone in treatment of overt hepatic encephalopathy. The American journal of gastroenterology 2013, 108(9):1458-1463.

7. Paik YH, Lee KS, Han KH, Song KH, Kim MH Moon BS, Ahn SH, Lee SJ, Park HJ, Lee DK et al: Comparison of rifaximin and lactulose for the treatment of hepatic encephalopathy: a prospective randomized study. Yonsei medical journal 2005, 46(3):399-407.

\section{VAI TRÒ CỦA DEXAMETHASONE TRONG BộC Lộ CỬA SỔ TRÒN CẤY ĐIÊ̂N CỰC ỐC TAI ĐỐI VỚI TRỞ KHÁNG IFT VÀ ĐÁP ỨNG THẦN KINH ART}

\section{TÓM TẮT}

Mục tiêu: Đánh giá vai trò của Dexamethasone (DEX) trong bộc lộ cửa sổ tròn cấy điện cực ốc tai đối với kết quả đo trở kháng IFT và đáp ứng thần kinh ART. Phương pháp nghiên cứu: nghiên cứu mô tả tiến cứu cócan thiệp được thực hiện trên 33 bệnh nhân cấy điện cực ốc tai từ tháng 8/2020 đến tháng 8/2021và được chia làm 3 nhóm: nhóm bơm DEX trong lúc bộc lộ cửa sổ tròn, nhóm nhúng điện cực vào DEX và nhóm không sử dụng DEX. Kểt quả nghiên cứu: trở kháng cao nhất đo được tại 1 kênh điện cực là $22,4(\mathrm{k} \Omega)$, thấp nhất là $1,21(\mathrm{k} \Omega)$. Giá trị trung bình tai tất cả các kênh là 4,22(k $\Omega)$. Trở kháng trung bình đo được tại các nhóm kênh điện cực đỉnh, giữa, đáy đều đat kết quả tốt $(<5 \mathrm{k} \Omega)$, trở kháng trung bình thấp nhất đo được tại nhóm nhúng $\mathrm{DEX}$ với giá trị là $3,97 \pm 0,88(\mathrm{k} \Omega)$, tiểp đến là nhóm bơm DEX với giá trị là $4,27 \pm 1,41(\mathrm{k} \Omega)$, cao nhất là nhóm không sứ dụng $D E X$ với kết quả là $4,48 \pm 1,28(\mathrm{k} \Omega)$, tuy nhiên sự khác biệt giữa các nhóm không có ý

*Trường Đại học y Hà Nội

Chịu trách nhiệm chính: Nguyễn Đức Minh

Email: nguyenducminhminhminh@gmail.com

Ngày nhận bài: 5.7.2021

Ngày phản biện khoa học: 31.8.2021

Ngày duyệt bài: 6.9.2021

\section{Nguyễn Đức Minh*, Cao Minh Thành*}

nghĩa thống kê với giá trị $p>0,05$. Kết quả đo đáp ứng thần kinh ART tỷ lệ đáp ứng tốt tại các nhóm điên cực đỉnh, giữa, đáy lần lượt là 72,$7 ; 81,8$ và $84,8 \%$. Kết quả đo đáp ứng thân kinh ART tai 3 nhóm bơm DEX, nhúng DEX và không sử dụng DEXsự khác biệt không có ý nghĩa thống kê với p> 0,05. Kết luâan: Vai trò của Desamethasone trong bộc lộ cửa sổ tròn cây điên cực ốc tai đối với kết quả đo trở kháng IFT và đáp ứng thần kinh ART không có sự khác biệt có ý nghĩa thống kê so với nhóm đối chứng.

Tư khóa: cấy điện cực ốc tai, dexamethasone, trở kháng, đáp ứng thân kinh

\section{SUMMARY}

THE ROLE OF DEXAMETHASONE IN

EXPOSING THE ROUND WINDOW IN COCHLEAR IMPLANT SURGERY ON

IMPEDANCE IFT AND NERVE RESPONSE ART

Objective: Evaluation of the role of Dexamethasone (DEX) in exposing the round window in cochlear implant surgery on impedance field telemetry (IFT) and auditory nerve response telemetry (ART). Methods: prospective intervention research on 33 patients having operated cochlear from 8/2020 to $8 / 2021$ and was divided into 3 groups: pump DEX during exposingthe round window, electrode dip in DEX and the group doesn't use DEX. Results: The resultsimpedance field telemetry for the highest 